\title{
As Nações-Unidas e os direitos do homem.
}

\author{
o Professor Antônio de Sampaio Dória, Delegado do \\ Brasil à VIII Sessão da Assembléia Geral das Nações \\ Unidas, pronunciou em francês, na III Comissão Social \\ e Humanitária o seguinte discurso:
}

Pacto entre todos os povos da terra sôbre as prerrogativas do homem, por ser homem, como, em 1787, na Declaração dos treze Estados dos Estados Unidos da América, e, dois anos depois, na Revolução Francesa, é, sem dúvida, ideal cuja flâmula, arvorada pelas Nações Unidas, the há de tremular, sempre, como um dia de glória.

Até onde, porém, podem ir as Nações Unidas num pacto desta amplitude e profundidade?

Cada nação em particular, como nós os indivíduos, pode pleitear as causas que entenda, como, onde, quanto e quando lhe pareça bem. É soberana. Mas, como membro das Nações Unidas, está adstrita aos deveres de fidelidade à Carta de São Francisco.

Esta carta é um sistema de propósitos e princípios, a espera de intérpretes para a uniformidade de sua aplicação. Firmada em junho de 1945, ainda quando se ignorava a extinção da vida, na terra, pelas armas atômicas, a Carta das Nações Unidas não ousou organizá-las em federação, nem confederação dos Estados Unidos do Mundo. Mercê da experiência amarga da "Sociedade das Naçôes", com sede em Genebra, a que o veto do Senado dos Estados Unidos da América negou o concurso dos Estados Unidos, as Nações Unidas, que a Carta de São Francisco ideou, 
estão, apesar de tudo, bem aparelhadas para a futura organização onipotente das nações.

\section{O fim supremo das Nações Unidas}

O que hoje, porém, lhes dá ânimos para os embates que vêm suportando, é o supremo propósito com que se anuncia: a paz e a segurança internacionais. Para a solução das desavenças ou litígios de Estado a Estado, as Nações Unidas substituem, ou prometem substituir, o direito do mais forte pela fôrça do direito, sem distinção de grandes ou pequenas potências. Para isto, como declara o artigo $1 .^{\circ}$, tomam as Nações Unidas, coletivamente, desde o artigo $39 .^{\circ}$ ao $50 .^{\circ}$, medidas efetivas, com que anulem ameaças à paz, ruptura da paz, e atalhem e reprimam atos de agressão, e com que cheguem, de conformidade com os princípios de justiça e do direito internacional, "a um ajuste ou solução das controvérsias ou situações que possam levar a uma perturbação da paz"

\section{Outros fins}

Ao lado desta grande e nobre finalidade, a que quase tudo o mais se reduz, se empenham as Nações Unidas em quatro outros propósitos. Três secundários, e um transitório.

\section{Fim transitório}

O transitório era para os tratados que projetaram da paz, com que se esperava dar por encerrada a segunda guerra mundial. Sonhando com tratados inspirados na lei do direito, se comprometeram os beligerantes, no artigo 77, parágrafo $10^{\circ}$ da Carta, já às vésperas do arrazamento de Hiroshima, a submeter à tutela: 
"os territórios que possam ser separados dos Estados inimigos, em conseqüência da segunda guerra mundial."

E, no parágrafo $2 .^{\circ}$ do artigo 53 , se definia por Estado aึnimigo:
"qualquer Estado que, durante a segunda guerra mundial, foi inimigo de qualquer signatário da Carta."

Ficou assentado, no capítulo XII, artigo 77, o sistema de tutela para os "territórios atualmente sob mandato" da extinta Sociedade das Nações, subseqüente à primeira guerra mundial.

Nestes compromissos, porém, ressalva o artigo 107: “ Nada invalidará ou impedirá qualquer ação que entenđa com o Estado inimigo de qualquer dos signatários da Carta", em virtude da segunda guerra mundial.

Já o artigo 53 excetuara da competência do Conselho de Segurança, em favor dos Estados em guerra com a Alemanha, Japão e Itália, medidas que fôssem determinadas em conseqüência do artigo 107.

Tôdas estas disposições da Carta das Nações Unidas são, por sua natureza, disposições transitórias. Liquidada a segunda guerra mundial, com a paz que ainda se espera, estas disposições podem ser riscadas da Carta.

\section{Propósitos secundários}

De par com êste propósito, a Carta de Sã̉o Francisco acena com três propósitos, abaixo da finalidade suprema da paz:

1 - autodeterminação dos povos, isto é: o direito a tôdas as nações de se governarem a si 
mesmas, desenvolvendo, nas colônias e territórios sob tutela, capacidade de govêrno próprio;

2 - garantia efetiva dos direitos do homem, das liberdades individuais, que cada Estado deve assegurar dentro de suas fronteiras, sem distinção de raça, política, sexo, língua ou religião;

3 - ajuda das Nações Unidas, mediante assistência técnica, e recursos materiais, aos povos sub-desenvolvidos, para que possam alcançar nível razoável de vida, criando condições de estabilidade e bem estar, "necessárias às relações pacíficas e amistosas entre as nações"

São êsses os três propósitos tributários à finalidade suprema da paz e da segurança internacionais.

\section{Autodeterminação dos povos}

O mais inflamável dos três é o da autodeterminação dos povos, disciplinado nos capítulos XI, XII e XIII da Carta.

O capítulo XI trata dos povos que a Carta apelidou de não-autônomos. São as colônias e protetorados.

Os capítulos XII e XIII tratam dos territórios tutelados. São os territórios novos, ou desmembrados dos Estados vencidos na II Guerra, ou voluntàriamente colocados sob tutela pelos Estados responsáveis por sua administração.

Todos êles (as colônias, os protetorados e os territórios tutelados) podem vir a ser Estados, como organizações da soberania que, com o desenvolvimento da capacidade de govêrno próprio, venham a adquirir.

Mas, por serem diferentes as duas categorias de territórios, diferentes hão de ser suas relações com as Nações Unidas. 
Nos territórios tutelados, o poder político pertence, virtualmente, às Nações Unidas que o exercem através de um Estado mandatário.

Nos territórios não-autônomos, o poder político, jurisdicional e administrativo, é, não por delegação, mas por direito próprio do Estado de que sejam colônias ou protegidos. A respeito dêsses territórios, há um problema de soberania, extranha de todo aos territórios sob tutela.

Desta diferença de categorias, resultam, necessáriamente, duas atitudes das Nações Unidas, em face dos territórios, com aspirações a Estados.

1 - Tratando-se dos territórios tutelados as Nações Unidas podem e devem promover a libertação dêles, nos têrmos dos capítulos XII e XIII, mediante decisões que tomem.

2 - Tratando-se de territórios não-autônomos, os membros das Nações Unidas, que assumiram ou assumam, segundo o artigo 73 da Carta, responsabilidade pela administração dêles, aceitaram, "como missão sagrada, a obrigação de promover, no mais alto grau, dentro do sistema de paz e segurança internacionais estabelecido" na Carta, a capacidade de govêrno próprio dos territórios que administrem.

E, no desempenho dêste encargo, os Estados que os administrem, estão no dever de:

1 - desenvolver, neles, a capacidade de govêrno próprio, tomando devida nota de suas aspirações políticas, e auxiliando-os no desenvolvimento progressivo de suas instituições políticas, "de acôrdo com as circunstâncias peculiares a cada território e seus habitantes, e os diferentes graus de seu adiantamento. (Artigo 73 letra $b$ )"; 
2 - transmitir regularmente ao Secretário Geral a título informativo, e dentro dos limites que a segurança e considerações de ordem constitucional imponham, informações estatísticas, ou de outro caráter técnico, relativas às condições econômicas, sociais e educativas dos territórios pelos quais são responsáveis (Artigo 73 letra $c$ ).

Enquanto a libertação dos territórios tutelados pode ser proclamado por deliberação das Nações Unidas, o juiz do desenvolvimento progressivo dos povos não-autônomos é o próprio Estado a que estão sujeitos. O papel das Nações Unidas se deve limitar a recomendações, sugestões sem caráter coativo. De posse das informações que recebam, em tôda a fase de aprendizado para a independência, as Nações opinam, sugerem, recomendam. Não determinam, porque não têm jurisdição nos territórios não-autônomos, como a têm nos territórios sob tutela.

Será pouco para os idealistas, fora das Nações Unidas. Dentro destas, porém, o juiz da capacidade para govêrno próprio das colônias ou protetorados é o Estado sob cuja jurisdição vivam. Às Nações Unidas cabem, apenas, recomendações. A mais não pactuaram os membros das Nações Unidas.

Por mais empenho que tenham em reconhecer, nos povos sob colônia ou protetorado, logo que atinjam capacidade de govêrno próprio, soberania com que se constituam em Estados, as Nações Unidas hão de ter os olhos postos em sua razão máxima de ser: manter a paz $e$ a segurança internacionais. Por isto e para isto, foi que adotaram os três propósitos de ordem secundária, um idealista e humanitário: o princípio da auto-determinação, e os outros preventivos contra hostilidades emergentes: o reconhecimento dos direitos do homem, e o desenvolvimento econômico dos povos subdesenvolvidos. 


\section{As soberanias nacionais}

Tão vivo foi, sempre, nas Nações Unidas, o propósito da paz entre as nações, que, depois de anunciado no artigo $1^{\circ}$ n. $^{\circ} 1^{\circ} .^{\circ}$, reafirma a Carta o mesmo princípio, em outros têrmos, no artigo $2 .^{\circ}$ n. ${ }^{\circ} 7^{\circ}$.

$O$ respeito à soberania de cada nação eqüivale à supressão da guerra. Manter a paz entre os Estados é manter a soberania de cada um. Quando uma nação recorre às armas contra outra, o que leva em propósito, é impor-lhe a vontade, e, pois, suprimir-lhe a soberania, só lha restituindo (se lha restituir), quando resolva. Se as Nações Unidas respeitarem e fizerem respeitar a inviolabilidade das soberanias nacionais, lograda terão a paz entre as Nações. Se as Nações Unidas mantiverem a paz entre os Estados que as compõem, lograda terão a inviolabilidade da jurisdição privativa de cada um. Imaginar que se mantém a paz, sem o respeito à jurisdição interna de cada Estado, o mesmo seria que supor a vida do homem, suprimindo-lhe o coração. $O$ coração da paz é o respeito às. soberanias nacionais.

Por esta razão, é que não têm as Nações Unidas, como. lhes cabe nos territórios sob tutela, a prerrogativa de declarar maioridade política a um povo sob colônia ou protetorado. Isto é prerrogativa do Estado que os administre.

A interpretação exata do Capítulo XI da Carta não contraria o princípio dos princípios que regem a organização das Nações Unidas: manter a paz universal, na inviolabilidade das jurisdições internas de cada Estado. A Carta é um sistema de propósitos e princípios, nenhuma de cujas partes pode ser concebida à parte, como se fôra independente. Tôdas se hão de compreender e aplicar, segundo os princípios que a inspiraram, principalmente os que a Carta declara, de modo formal, sem abrir exceções.

Pois, o princípio que a Carta declara, sem abrir exceções, é êste: nada, absolutamente nada na Carta, autoriza. 
as Nações Unidas a intervirem em negócios da jurisdição interna de qualquer Estado.

É o que examinaremos daqui a pouco.

\section{Os direitos do homem}

Além do propósito transitório sôbre a liquidação da II Guerra Mundial; além do propósito que, a serviço da paz e da segurança internacionais, visa reconhecer soberania aos territórios com capacidade para govêrno próprio, dois outros propósitos secundários a Carta preceitua.

Um é o enunciado no artigo $1 .^{\circ} 3 .^{\circ}$ :

“promover e estimular o respeito aos direitos humanos $e$ às liberdades fundamentais para todos, sem distinção de raça, sexo, língua ou religião."

A garantia real dos direitos do homem seria o supremo ideal da civilização política. A cada Estado cabe primordialmente êste dever. Só êle tem, por ser soberano, o poder de determinar sua própria competência. A garantia dos direitos do homem são limites ao poder público. E só o próprio poder público soberano pode limitar-se a si mesmo.

Com estimular e promover o respeito aos direitos do homem já prestam as Nações Unidas grande serviço à humanidade. Criam atmosfera propícia à paz universal.

\section{Ajuda às nações subdesenvolvidas}

O outro propósito secundário, isto é: subsidiário do propósito da paz universal, é: 
"a cooperação das Nações Unidas aos povos subdesenvolvidos com assistência técnica e recursos materiais,

para que possam alcançar alto nível de vida, mediante:

"desenvolvimento econômico, social, cultural $e$ humanitário",

e, assim, criar uma atmosfera favorável à paz.

\section{A Jurisdição interna dos Estados}

A ajuda das Nações Unidas aos povos subdesenvolvidos não suplanta porém, nem poderia suplantar o que dispõe o artigo $2 .^{\circ}$ e seu $7 .^{\circ}$ :

“a Organização e seus Membros, para a realização dos propósitos mencionados no artigo $1^{\circ}$, agirão de acôrdo com os seguintes princípios:

7..$^{\circ}$ - Nenhum dispositivo da presente Carta autorizará as Nações Unidas a intervirem em assuntos que dependam essencialmente da jurisdição interna de qualquer Estado, nem obrigará os membros a uma solução nos têrmos da presente Carta."

E, para evitar qualquer sofisma com que se abrisse brecha à inviolabilidade das soberanias de cada Estado, o mesmo parágrafo continua:

“êste principio, porém, não prejudicará a aplicação das medidas coercitivas do Capítulo VII”.

Estrutura-se o parágrafo $7 .^{\circ}$ do artigo $2 .^{\circ}$ de três partes. 
A primeira afirma o princípio: nada, na Carta, autoriza as Nações Unidas a intervirem na jurisdição interna de qualquer Estado.

Nada, nenhum dispositivo, seja qual fôr. Não se poderia ser mais formal. Não se podia advertir com mais energia, contra qualquer dispensa. É a coluna mestra, sem trincas ou fisgas, por onde se insinue uma exceção.

Anuncia a Carta o propósito de algumas bases, para os tratados de paz com os inimigos da II Guerra Mundial?

Nada, na Carta, autoriza as Nações Unidas a violarem a jurisdição interna de Estado que lhes seja membro.

Anuncia a Ciarta o propósito de auto-determinação dos territórios não-autônomos?

Nada, na Carta, autoriza as Nações Unidas a coagirem o Estado a cuja jurisdição estejam êsses territórios.

Anuncia a Carta o propósito de promover e estimular a garantia dos direitos do homem?

Nada, na Carta, autoriza as Nações Unidas, a pretexto de garantias de liberdades fundamentais a todos, sem distinção de raça, sexo, língua ou religião, a intervirem em. assuntos que dependam essencialmente da jurisdição interna de qualquer Estado.

Anuncia a Carta o propósito de cooperação aos povos. subdesenvolvidos, mediante assistência técnica e ajuda material, para seus desenvolvimento econômicos, culturais, educativos, higiênicos, sociais?

Nada, na Carta, autoriza as Nações Unidas a irem além de oferecer ajuda, ou atender a pedidos de cooperação, que lhes façam os povos subdesenvolvidos.

E porquê essa rigidez: nada ou nenhuma disposição da Carta? Porquê princípio assim tão formal? tão sem exceção? que mereça tão solene respeito?

É porque, na inviolabilidade da soberania de cada Estado, quanto aos assuntos de sua jurisdição interna, estấ a essência da paz e da segurança internacionais, para cuja obtenção se criaram as Nações Unidas. Quem não 
reconhecer a identidade entre a paz universal e o respeito. à jurisdição interna de cada Éstado, por certo terá distante de si o espírito das Nações Unidas. Sem esta identidade, seria admitir, no organismo internacional, para assegurar a paz entre as nações, órgãos cuja função fôsse aniquilá-la. Seria insuflar vida a um organismo, e lhe injetar, ao mesmo tempo, nas veias, o germe de sua destruição.

A segunda parte no parágrafo $70^{\circ}$ é esta:

“Nada, na Carta, obrigará os membros das Nações Unidas a submeterem os assuntos que entendam com sua jurisdição interna, a uma solução nos têrmos desta Carta."

E o reverso do princípio de que nada, na Carta, autorizará as Nações Unidas a intervirem na jurisdição interna de qualquer Estado.

A terceira proposição, encartada no parágrafo $7 .^{\circ}$, adverte:

“êste princípio, porém, não prejudicará a aplicação das medidas coercitivas constantes do Capítulo VIII."

O de que dispõe êste capítulo, é a "ação relativa às ameaças à paz, ruptura da paz, e atos de agressão."

Ora, ato de agressão de um Estado a outro são atentados à soberania do Estado agredido. A aplicação das. medidas coercitivas contra o agressor o que visam, é resguardar ou restabelecer a inviolabilidade da soberania do Estado agredido.

Logo, longe de serem as medidas coercitivas do Capítulo VII exceção ao princípio do artigo $2 .^{\circ} \mathrm{n} .^{\circ} 7 .^{\circ}$, o que se reafirma, neste Capítulo, é a inteireza do princípio, sua garantia, quando ameaçado, ou violado por atos de agressão. 
$0 \S 7 .^{\circ}$ do artigo $2 .^{\circ}$ da Carta é realmente singular. Singular, porque tudo, na Carta, se condiciona a êle. Singular, porque nada, na Carta, autoriza a excetuá-lo.

\section{Classificação dos fins das Nações Unidas}

$\mathrm{Na}$ interpretação da Carta de São Francisco, é preciso não perder de vista a escala dos propósitos a cargo das Nações Unidas.

Um, supremo, a que os demais servem. É a paz entre as nações, a segurança internacional, na inviolabilidade da jurisdição interna de cada Estado.

Outros, secundários, para a efetividade do supremo. São três :

1 - a auto-determinação dos povos capazes, hoje sob a tutela das Nações Unidas, ou de membros das Nações Unidas;

2 - a garantia dos direitos do homem sem distinção de raça, sexo, língua ou religião; e

3 - cooperação, mediante assistência técnica e ajuda material, no desenvolvimento econômico, social, educativo e humanitário dos povos subdesenvolvidos.

Resta o transitório. São compromissos entre os membros das Nações Unidas, beligerantes da II Guerra Mundial.

$\mathrm{Na}$ escala de valores, quem não vê a primazia no propósito de manter a paz entre as Nações?

Dentro desta visão de conjunto, é que se há de aplicar o princípio da auto-determinação, o princípio dos direitos do homem e da ajuda às nações subdesenvolvidas.

Dois problemas na adoção dos direitos do homem

O trabalho já realizado pelas Nações Unidas, para defender as liberdades do homem, e para disseminar as idéias 
liberais, implícitas na declaração dos direitos do homem, já deve ter produzido benefícios inestimáveis.

Não são, porém, poucos nem fáceis os embaraços ainda por vencer. O propósito de uma adoção universal dos direitos do homem envolve dois problemas, cujas incógnitas nem todos os povos sabem ou querem decifrar.

Um é o de precisá-los, e o outro é o de garantí-los.

A êstes dois problemas, o Brasil me parece ter adotado, para suas condições peculiares, suas tradições, a índole de seu povo, a solução melhor e mais sábia.

Já na Constituição de 1824, nos primórdios da independência do país; depoìs, em 1889, na Constituição que substituiu o Império pela República, e, afinal, em 1946, na Constituição que hoje lá vigora, têm sido consagrado, em norma invariável, a inviolabilidade em têrmos amplos dos direitos concernentes à vida, à liberdade, à segurança individual e à propriedade. E não só aos brasileiros, mas também aos estrangeiros residentes no país.

\section{A tradição liberal do Brasil}

No Brasil, todos são iguais perante a lei. Não há previlégios de nascimento, nem foros de nobreza.

Ninguém é obrigado a fazer, ou deixar de fazer alguma cousa, senão em virtude de lei.

A lei não prejudicará o direito adquirido, o ato jurídico perfeito, e a cousa julgada.

É livre a manifestação de pensamento, respondendo cada qual pelos abusos que cometer.

É inviolável a liberdade de consciência e de crença, assegurado o livre exercício dos cultos religiosos.

É respeitado o sigilo de correspondência.

A casa é o asilo inviolável do indivíduo.

Todos podem reunir-se sem armas, não intervindo a polícia, senão para assegurar a ordem pública. 
E garantida a liberdade de associação para fins lícitos.

É livre o exercício de qualquer profissão, observadas as condições de capacidade que a lei estabelecer.

É garantido o direito de propriedade, salvo desapropriação por necessidade ou utilidade pública, mediante prévia indenização.

Ninguém pode ser preso, senão em flagrante delito, ou por ordem escrita da autoridade competente.

Não haverá fôro previlegiado, nem juízes e tribunais de exceção.

Ninguém pode ser processado, senão pela autoridade competente, e na forma de lei anterior.

Nenhuma pena passará da pessoa do delinquente.

Não haverá pena de morte, de banimento, de confisco, nem de caráter perpétuo.

Nenhum tributo será exigido ou aumentado sem lei que o estabeleça; nem cobrado, em cada exercicio, sem prévia autorização orçamentária.

É assegurado o direito de petição aos poderes públicos, contra abusos das autoridades, e de promover a responsabilidade delas.

Por esta amostra, já se pode fazer idéia da tradição liberal, que se apurou no Brasil.

\section{Garantias reais dos Direitos do Homem}

O mais difícil, porém, dos dois problemas sôbre os direitos do homem é saber como garantí-los. Declarações no papel valem menos que nada. $O$ que realmente interessa, são as instituições permanentes e os processos judiciários, que lhes garantam a aplicação.

a) Processos Judiciários - Os mais sábios instrumentos judiciários, para o restabelecimento rápido e eficaz dos direitos do homem, violados por abusos do poder, são, em meu país, dois: o hábeas-corpus e o mandado de segurança. 
Aquêle, para a garantia da liberdade de locomoção, contra coação ou violência, por ilegalidade ou abuso de poder. Êste, para proteger direito líquido e certo, não amparado pelo hábeas-corpus, seja qual fôr a autoridade responsável pela ilegalidade ou abuso de poder.

b) Instituições Permanentes - As medidas judiciárias, porém, por si sós, não bastam. São necessárias instituições permanentes na estrutura geral do Estado.

c) Independência e harmonia dos 3 poderes - Em meu país, a primeira instituição de garantia dos direitos do homem é a divisão dos poderes em três, independentes e harmônicos entre si: o que faz a lei, o que a executa, e o que dirime os litígios, aplicando a lei aos fatos alegados e provados.

Onde todos os poderes se concentram numa só pessoa, já o proclamara Montesquieu, a tirania reinará, e, com ela, nenhuma garantia positiva para os direitos do homem.

Longe de um curso de direito público, toco de leve em princípios sem os quais as liberdades individuais, ainda que declaradas na lei, ficariam letra morta.

Não só a independência e harmonia dos três poderes. - Mas igualmente condições de imparcialidade, competência e firmeza do poder judiciário, com a escolha de seus membros pelo Chefe do Executivo com aprovação do Senado, e com assegurar aos juízes vitaliciedade, irremovibilidade e irredutibilidade de seus vencimentos.

d) Inconstitucionalidade de leis - A segunda providência constitucional, no Brasil, para a garantia efetiva dos direitos do homem é vedar ao Congresso abolir, por leis ordinárias, a declaração constitucional dos direitos do homem. E, por isto, quando, acaso, estatuir lei contrária às liberdades individuais, esta lei não é aplicada pelos tribunais, para que possam aplicar a lei constitucional.

Nem todos estarão habituados ao problema da inconstitucionalidade de leis. Estando declarados, na Constituição, os direitos do homem, não pode o legislador ordinário menosprezá-los. E, se o fizer, incumbe ao Poder Judiciário 
amparar, contra abusos de poder, nas resoluções do Congresso, ou em atos administrativos, os direitos fundamentais do homem.

A garantia judiciária contra exorbitâncias da lei ordinária, ou contra abusos da administração, é a maior maravilha que já concebeu o gênio político de um povo em todos os tempos, e devemo-la aos patriarcas da independência dos Estados Unidos, e a Marshall, a maior glória de sua magistratura.

A Justiça, no jôgo dos poderes, fala sempre por último, e todos respeitam, sem vacilações, as sentenças que profira.

e) O Regime Democrático — E ainda não é tudo. Com a independência e harmonia dos três poderes do Estado; com a garantia judiciária dos direitos do homem contra abusos do poder legislativo ou executivo; a experiência política milenária aconselha, para real garantia dos direitos do homem, a abolição da onipotência irresponsável de um homem sôbre todo o povo sem voz e sem voto, e adoção consequente do regime democrático.

Democracia é palavra estragada, equívoca e maltrapilha, em virtude das aplicações que tem tido.

No Brasil, democracia é o consentimento do povo na investidura e no exercício do poder. Na investidura, quando elege, pelo voto secreto e apuração judiciária, seus governantes. No exercício, quando lhes fiscaliza os atos, na imprensa, e nos comícios. Ora condena, ora aplaude, e, aplaudindo, reitera sua confiança nas urnas.

Sem um conjunto de princípios, de providências, pesos e contra pesos, e uma longa tradição de lutas liberais, a garantia dos direitos do homem é ilusória.

\section{Respeito às soberanias nacionais}

Que podem as Nações Unidas fazer, nesta matéria, além de recomendações, além de sugestões sôbre a excelência dêste ou daquele instituto de garantia? 
Basta considerar que a declaração constitucional dos direitos do homem, em qualquer país, importa em limitar as atribuições ao poder de legislar, e ao poder de administrar. Os direitos fundamentais são barreiras, opostas ao exercício do poder público.

Ora, só o Estado é competente, para determinar sua competência.

Logo, só cada Estado, sem a menor interferência de poder estranho, pode garantir, contra abusos de poder, os direitos do homem. Sem prejuizo da exclusão das Nações Unidas, que o artigo 6 da Carta comina ao Estado que insista em infringir os princípios da Organização, a garantia internacional, direta, e dentro dos países, que acaso advoguem, é incompatível com a inviolabilidade das soberanias nacionais.

Bem hajam as Nações Unidas pelo trabalho de propagar, no mundo, os direitos do homem. No dia em que todos os Estados adotarem as garantias reais dêstes direitos, o caminho estará desbravado, para a segurança de todos.

Têm, pois, o apoio da Delegação brasileira os projetos de resolução, que convidam o Conselho Econômico e Social a prosseguir, de acôrdo com o artigo 55 da Carta, o exame dos projetos sôbre "o respeito universal e efetivo dos direitos do homem e das liberdades fundamentais, sem distinção de raça, sexo, língua ou religião".

E' o a que se comprometeram, no artigo 56 da carta, todos os Membros da Organização.

$\mathrm{O}$ ideal em marcha, Senhor Presidente, é que os direitos do homem sejam as fronteiras naturais do poder político. No dia em que êste ideal fôr reconhecido, não haverá mais, no mundo, nenhum govêrno absoluto, e nenhum homem escravo, e a paz reinará sôbre a terra. 